\title{
Planejamento de Carreira através de um objeto de aprendizagem
}

\author{
Daniela Forgiarini Pereira \\ Magda Bercht \\ Magalí Teresinha Longhi \\ Programa de Pós-Graduação em Informática na Educação (PPGIE) \\ Universidade Federal do Rio Grande do Sul (UFRGS) \\ CEP 90.040-060 - Porto Alegre, RS - Brasil \\ \{dfpr@terra.com.br; bercht@inf.ufrgs.br; mlonghi@cesup.ufrgs.br\}
}

Resumo: Este artigo apresenta um estudo para o desenvolvimento de um objeto de aprendizagem (OA) que pretende ser um recurso que permita ao aluno encontrar subsídios de autoconhecimento para melhor planejar e gerir sua carreira profissional, o CarreiraEAD. Traz como suporte as teorias de London, Stumph e Hall e, como modelo de $\mathrm{AO}$, as arquiteturas pedagógicas.

Palavras-chaves: planejamento de carreira a distância; educação de carreira através de objetos de aprendizagem.

Abstract: This paper presents a study for the development of a learning object (LO) supposed to be used as a resource that allows pupils to find elements of self-knowledge which will help them in their career planning and management - the "CarreiraEAD". It uses London, Stumph and Hall theories as its basis and takes as LO model the pedagogical architectures.

\section{Introdução}

Beck (2001) reconhece Objeto de Aprendizagem (OA) como qualquer entidade, digital ou não digital, que possa ser usada, reutilizada ou referenciada durante o uso de tecnologias que suportem o ensino.

Os objetos de aprendizagem possibilitam ao sujeito engajar-se de forma independente e autônoma para aprender por descoberta. Sendo assim, tais objetos são recursos importantes para o apoio às ações de educação a distância ou para o uso em cursos presenciais.

O objeto de aprendizagem de Planejamento de Carreira - CarreiraEAD disponibilizado on-line está sendo desenvolvido para auxiliar os professores, principalmente os professores-psicólogos, no trabalho de planejamento de carreira, facilitando o trabalho de educação do indivíduo em sua preparação para um futuro profissional. A modalidade a distância visa ampliar a possibilidade de acesso ao processo de orientação da carreira para estudantes de graduação e profissionais do mercado de trabalho, além de ser um recurso para professores de Psicologia tornarem 
suas aulas mais interativas. Pesquisas apontam que alunos com maior autoconhecimento e que possuem suas carreiras planejadas são mais motivados e conseguem com facilidade alcançar seus objetivos. Entretanto, poucos alunos possuem acesso a esse tipo de trabalho presencial, sendo o mesmo oneroso e com condições que limitam o número de orientandos, o que justifica a construção desse objeto.

Dessa forma, esse objeto de aprendizagem deve ser modulado para dar retornos diferentes de acordo com o estado de ânimo dos orientandos. Como hipótese, sugere-se que, se os psicólogos adaptarem o seu trabalho de planejamento de carreira às características de personalidade dos orientandos e aos seus estados de ânimo, a eficácia e a eficiência da intervenção será maior.

Este artigo aborda a modelagem de um OA para apoiar o aluno em sua gestão de carreira. A seção 2 apresenta a necessidade de planejamento de carreira pelo aluno e algumas teorias que fundamentam tal trabalho. A seção 3 discute a necessidade de abordar a afetividade na modelagem de um objeto que se volta ao planejamento de carreira e a seção 4 descreve o OA em desenvolvimento.

\section{Planejamento de Carreira}

A educação de carreira, na qual o planejamento e a gestão de carreira são partes, é uma forma de educação que deveria ser inserida na escola ainda durante o ensino fundamental. Muitos estudantes não se sentem aptos a fazer uma escolha profissional madura quando terminam o ensino médio porque não foram ensinados e estimulados para isso. Em estudos posteriores, pretende-se ampliar a abrangência do objeto para outros níveis de escolaridade e para utilização de outros profissionais.

London e Stumph (1982) definem carreira como a sequência de posições ocupadas e de trabalhos realizados durante a vida de uma pessoa, envolvendo uma série de estágios e a ocorrência de transições que refletem necessidades, motivos e aspirações individuais, além de expectativas e imposições da organização e da sociedade. $\mathrm{Na}$ perspectiva do indivíduo, a carreira é composta pelo entendimento e pela avaliação de sua experiência profissional, enquanto da perspectiva da organização, engloba políticas, procedimentos e decisões ligadas a espaços ocupacionais, níveis organizacionais, compensação e movimento de pessoas. Essas perspectivas são conciliadas pela carreira dentro de um contexto de constante ajuste, desenvolvimento e mudança.

Segundo Greenhaus (1999), a gestão de carreira é um processo pelo qual indivíduos desenvolvem, implementam e monitoram metas e estratégias de carreira, pressupondo que a otimização desses processos, através de uma gestão estruturada de carreira, resulta em indivíduos mais produtivos e autorrealizados.

Martins (2001) complementa essa definição, demonstrando a importância da continuidade desse processo ao longo do tempo. Para isso, seria necessário o indivíduo seguir algumas premissas básicas como coletar informações sobre si e a respeito do mundo do trabalho, traçar um perfil detalhado de suas características de personalidade, interesses e aptidões, bem como inventariar as possibilidades de atuação no mercado de trabalho e ocupações alternativas. Desse modo, estabelecerá metas realistas baseadas nas informações coletadas, além de implementar uma estratégia para o alcance das metas. 
Para Dutra (1996), um modelo de planejamento de carreira tem como principais objetivos desenvolver nas pessoas um espírito crítico diante do seu comportamento em relação à carreira, estimular e dar suporte a um processo de autoavaliação, oferecer estrutura para reflexão sobre sua realidade profissional e pessoal, disponibilizar ferramentas para desenvolver objetivos de carreira e planos de ação a fim de monitorar a carreira ao longo do tempo.

Hall (1986) propõe que o planejamento de carreira permite que a continuidade do trabalho de reflexão individual seja confrontada com opiniões de familiares, amigos e, eventualmente, parceiros de empresa.

O planejamento e gestão de carreira podem ser trabalhados a partir da necessidade do desenvolvimento de conhecimentos, habilidades e atitudes apropriados, levando o indivíduo a atender às necessidades impostas pelo mercado de trabalho. No Brasil, existem algumas instituições que já inseriram a disciplina de Planejamento de Carreira em seus currículos na graduação, como disciplina eletiva, de forma presencial, podendo citar como exemplos a Faculdade de Psicologia da Universidade Federal do Rio Grande do Sul (UFRGS), a Universidade Federal de Santa Catarina (UFSC) e a Universidade Estadual de Londrina (UEL). Entretanto, não existem, até o momento, instituições que fazem esse processo no formato a distância, situação que facilitaria o alcance a um maior número de alunos.

\subsection{Planejamento de carreira a distância}

A primeira questão que deve ser considerada é sobre a ética do trabalho dos psicólogos na internet. Nesse sentido, a resolução número 003/2000 do Conselho Federal de Psicologia (CFP) que regulamenta os serviços oferecidos pelos psicólogos na rede, e reconhece a orientação profissional como um dos possíveis serviços oferecidos por psicólogos mediados por computador.

Spaccaquerche (2005) montou e validou um programa de Orientação Profissional Online (OP Online), onde atendeu 851 adolescentes, na faixa de 15 a 20 anos. O trabalho foi desenvolvido em três momentos: autoconhecimento, informações sobre as profissões e mercado de trabalho, e, por fim, a escolha propriamente dita. Os resultados comprovaram que é possível desenvolver um trabalho de orientação profissional via internet de maneira proveitosa e eficiente para o orientando.

\section{Estados afetivos no planejamento de carreira}

Tratando-se de emoções, Kidd (2003) discute o quanto é importante entender o papel dos estados afetivos no planejamento de carreiras. Segundo esse autor, para entender melhor as atitudes e os comportamentos no trabalho, é preciso examinar o estado afetivo, a cognição e o comportamento apresentado em um determinado evento com significado emocional. Kidd (1998) apresenta uma pesquisa realizada em um grupo de empregados voluntários de cinco organizações do Reino Unido, na qual foram aplicados instrumentos de medidas e feitas entrevistas. Os resultados advindos do trabalho de pesquisa sugerem que as discussões sobre a carreira dos indivíduos podem 
promover um self-insight, facilitar o planejamento da carreira e ter impactos emocionais que melhoram a performance e o comprometimento com a organização.

Feldman (2003) examina os fenômenos associados à indecisão na escolha de carreira pelos jovens baseado em fatores como personalidade, interesses vocacionais, status demográfico, experiências de trabalho anteriores, ambiente familiar, além dos componentes cognitivos e afetivos do indivíduo. O componente cognitivo inclui a falta de objetivo ou direcionamento de carreira e isso inclui a falta de informação sobre si e a respeito do ambiente. $\mathrm{Na}$ dimensão afetiva, inclui a vivência de ansiedade, ambivalência, incertezas e desconforto, medo do comprometimento, sentimentos de falta de controle e frustração, principalmente relacionada ao trabalho atual e às aspirações de carreira

Salmela-Aro et all. (2009) afirmam que determinadas estratégias apresentadas durante o período da Universidade indicam o quanto o indivíduo se dedicará ou não à carreira escolhida. Emoções logrativas como otimismo, satisfação, sucessos significativos nas atividades acadêmicas demarcam um provável sucesso na carreira. Emoções negativas fazem com que o indivíduo não se foque nos trabalhos acadêmicos, criando estratégias de fuga e, por sua vez, gerando baixa perfomance na carreira escolhida.

\section{O Objeto de Aprendizagem}

O CarreiraEAD traz como tema principal o planejamento de carreira. A teoria que está embasando a construção desse objeto é a de Arquiteturas Pedagógicas (AP) (BEHAR, 2009). A AP é constituída por aspectos organizacionais (fundamentação do planejamento/proposta pedagógica, organização do tempo, expectativas dos participantes, etc.), conteúdo (materiais ou recursos informáticos utilizados), aspectos metodológicos (atividades, formas de interação, procedimento de avaliação, organização dos elementos, etc.) e aspectos tecnológicos (definição do ambiente virtual de aprendizagem - AVA - e suas funcionalidades, ferramentas de comunicação, entre outros).

No CarreiraEAD existe uma divisão em cinco módulos: avaliação de potencial, carreira e emoções, inventário do passado, análise do presente e planejamento do futuro. Cada módulo conta com atividades em forma de desafios, os quais têm como elementos disparadores das discussões: análise crítica de materiais, resolução de problemas, bem como o uso de ferramentas de comunicação e colaboração. Assim, acredita-se que é possível trabalhar as competências necessárias para o planejamento de carreira, como por exemplo, o comportamento exploratório e o empreendedorismo.

Além desses recursos, o objeto de aprendizagem CarreiraEAD vai disponibilizar apresentação, guia, glossário e material de apoio, conforme Figura 1.

Cada módulo disponibiliza um texto introdutório ao assunto, sensibilizando para o tema e para o fato da necessidade da importância da escolha profissional. Além disso, os módulos possuem dois desafios - que são atividades de autoconhecimento - leitura complementar e vídeo. No texto, palavras que podem causar dúvidas ao orientando são descritas no Glossário, apresentando links no próprio texto. Na leitura complementar, 
disponibilizam-se artigos sobre o assunto. No vídeo, são apresentadas imagens que sensibilizam para a importância do planejamento de carreira ainda durante a faculdade.

As atividades de autoconhecimento, relacionadas como desafios no OA CarreiraEAD, incluem a atividade de Âncoras de Carreira (SCHEIN, 1996), a realização da atividade de feedback (PEREIRA \& TONDO, 2008), o mapeamento das competências (BOLLES, 1996), além de atividades de coaching (MINOR, 2003).

O comportamento exploratório, a autonomia, a iniciativa, a capacidade de abstração, o empreendorismo e o interesse em autoconhecimento são exigidos conforme o tema e os desafios propostos. Tais módulos podem ser explorados de forma livre ou na ordem em que são dispostos no objeto.

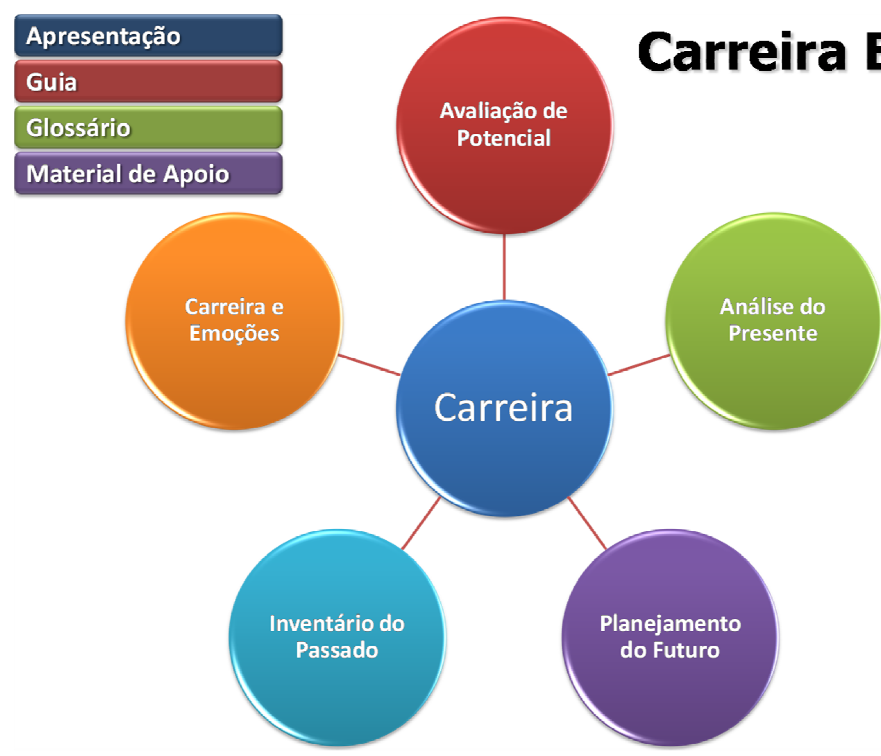

Figura 1 - Interface do Carreira EAD

\subsection{Estados afetivos e o objeto de aprendizagem no Carreira EAD}

$\mathrm{Na}$ identificação da afetividade em uma "comunicação face a face", a emoção do transmissor, além de ser percebida em tempo real, pode se adequar ao estado afetivo do receptor ao longo da comunicação. Já em um meio tecnológico, a percepção da afetividade pelo receptor é muitas vezes prejudicada pelo tipo de interação possível. Basicamente, a interação é efetuada por ferramentas de comunicação textuais (fóruns, "chats", "blogs", etc.), embora, atualmente, haja recursos tecnológicos que permitem um 
reconhecimento por meio das expressões faciais, da entonação da voz e dos movimentos corporais (Behar et al., 2009).

Através da introdução de dispositivos para reconhecimento dos estados afetivos no OA, como o CarreiraEAD, pode-se verificar os aspectos afetivos presentes nas relações estabelecidas entre o sujeito e o objeto de aprendizagem. Dentro desse contexto, as relações cognitivas e afetivas presentes nesta relação serão tratadas utilizando-se avaliação psicológica e uma escala de estados de ânimo.

Os estudos teóricos sobre os conceitos de afetividade, estados de ânimo, interação, entre outros, fundamentam o mapeamento dos aspectos afetivos que possam ser observados por um agente artificial. Por outro lado, também servem para apoiar a análise e compreensão dos dados observáveis dos alunos em interação (Longhi, 2009).

As emoções podem caracterizar determinados estados de ânimo, que, por sua vez, incluem também todas as respostas dos diversos componentes orgânicos do sujeito (Mayer \& Hanson, 1995). Assim, as emoções são classificadas em famílias afetivas, reunidas com base em extenso estudos teóricos e justificativas empíricas (Scherer \& Tran, 2001; Tran, 2004), posicionadas em um espaço de representação conforme apresentado na Figura 2. Este modelo, aqui denominado Roda dos Estados Afetivos (REA), será utilizado neste estudo para investigar os estados de ânimo durante a interação do usuário com os módulos do OA.

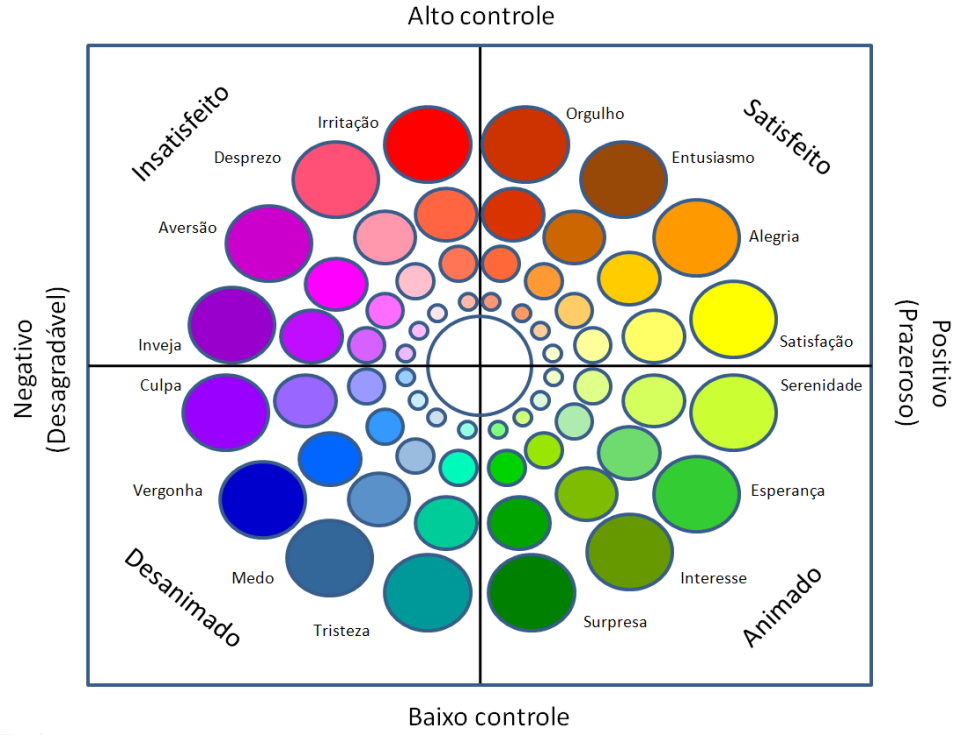

Figura 2. Espaço de representação dos estados de ânimo, baseado em Tran (2004).

Para este estudo, são consideradas quatro classes diferentes de estados de ânimo, conforme apresentado em Longhi et. al. (2009):

(1) $\underline{\text { Animado }}$ - implica demonstrar surpresa, interesse, esperança e serenidade para enfrentar os desafios da aprendizagem, colaborando e cooperando com os colegas. Estas famílias afetivas (surpresa, interesse, esperança e serenidade) têm valência 
positiva, baixo controle sobre os eventos e suas consequências (o aluno não tem controle sobre as diversas situações de aprendizagem), além de ser orientado ao futuro. São compostas por emoções condutivas, aquelas que imbuem o aluno de ânimo positivo para explorar, desenvolver e continuar o aprendizado.

(2) Desanimado - implica demonstrar tristeza, medo, vergonha e culpa por não conseguir acompanhar o conteúdo. Estas famílias afetivas têm valência negativa, baixo controle sobre os eventos e suas consequências, além de ser orientado à resignação. São compostas por emoções resignativas aquelas que podem levar o aluno a desistir do processo de aprendizagem. Contudo, podem ter implicações positivas no sentido de provocar um tempo de recuperação para repensar atitudes, readaptar-se a novas condições ou prevenir-se para não se envolver novamente na mesma situação.

(3) Satisfeito - implica demonstrar satisfação, alegria, entusiasmo e orgulho pela tarefa cumprida. Estas famílias afetivas têm valência positiva, alto controle sobre os eventos e suas consequências, aumentando a autoestima e o bem-estar. São compostas por emoções logrativas, aquelas que marcam a celebração do sucesso (Scherer \& Tran, 2001).

(4) Insatisfeito - implica demonstrar irritação, desprezo, aversão e inveja. Estas famílias afetivas têm valência negativa, alto controle sobre os eventos e suas consequências, aumentando, assim, a agressividade. São compostas por emoções antagônicas, aquelas em que o aluno pode alimentar um desejo por represálias ou vinganças.

Dessa forma, o modelo REA será incorporado ao OA CarreiraEAD para identificar o estado de ânimo do usuário nas diversas etapas de construção do seu planejamento de carreira. Em cada etapa, o aluno é solicitado a mensurar seu estado de ânimo. De acordo com os resultados, novas tarefas são solicitadas a fim de tornar o estado de ânimo do orientando animado e satisfeito. Por exemplo, se o aluno identificarse como desanimado e insatisfeito na etapa "Inventário do Passado", o psicólogo vai fazer uma intervenção com o intuito de motivar o orientando, antes de ele ir para a etapa seguinte.

A comprovação de que se trata de uma ferramenta válida será a avaliação de reação e da eficácia do treinamento (Boog \& Boog, 2006).

\section{Considerações Finais}

Este trabalho apresenta estudos iniciais sobre a construção de um objeto de aprendizagem de planejamento e gerenciamento de carreiras, provisoriamente denominado de CarreiraEAD, que comporte os fundamentos para o planejamento e gestão de carreira, servindo de instrumento para análise dos processos individuais de escolha e inserção no mercado de trabalho.

$\mathrm{O}$ objeto de aprendizagem CarreiraEAD trata de uma temática recorrente e necessária para proporcionar o processo de orientação profissional mais acessível a comunidades distantes e, neste caso, do planejamento de carreira a distância. Portanto, 
como próximos passos desse estudo, pretende-se disponibilizar o objeto para psicólogos e treiná-los para a aplicação e realização do processo de ensino de carreira a distância.

Sabe-se que o estudo está em fase inicial. Pretende-se, depois de concluído o objeto de aprendizagem, adaptá-lo a diferentes contextos educacionais, ampliando a sua possibilidade de atuação, com a disponibilização desse na rede.

Além disso, outros estudos podem ser incluídos a esse, como a inserção de web cam para melhor mensuração do estado afetivo do aluno por meio de suas expressões. Outra proposta possível é a inserção do CarreiraEAD em Universidades Corporativas dentro das empresas.

\section{Referências}

BECK, R.J. (2001) Learning objects: What? Center for Internation Education. Univesity of Wisconsin. Milwaukee.

BEHAR, P.A. (Org). Modelos Pedagógicos de Educação a Distancia. Porto Alegre: Artmed, 2009.

BOLLES, R. N. (1998) Como conseguir um emprego e descobrir a profissão dos seus sonhos. Rio de Janeiro: Salamandra.

BOOG, G.; BOOG, M. Manual de Treinamento e Desenvolvimento: gestão e estratégicas. São Paulo: Pearson Prentice Hall, 2006.T

DUTRA, J. S. Administração de Carreira: uma proposta para repensar a gestão de pessoas. São Paulo: Atlas, 1996.

GREENHAUS, J. H. et al. Career management. 3 ed. Orlando: Harcourt,1999.

HALL, D. (Org). Carrer development in organizations. San Francisco: Jossey-Bass, 1986.

LONDON, M.; STUMPH, S. Managing carrers. Addison-Wesley: Califórnia.

LONGHI, M. T.; PEREIRA, D. F.; BERCHT, M.; BEHAR, P. A. Um experimento para compreender como os aspectos afetivos podem ser reconhecidos em ambientes virtuais de aprendizagem. RENOTE: Revista Novas Tecnologias na Educação, v. 7, № 1, 2009.

MAYER, J. D. ; HANSON, E. Mood-congruent judgment over time. Personality and Social Psychology Bulletin, 21, 237-244. 1995. 
MARTINS, H. T. Gestão de Carreiras na era do conhecimento: abordagem conceitual \& resultados de pesquisa. Rio de Janeiro: Qualitymark Ed., 2001.

KIDD, J. The outcomes of effective career discussion at work. Journal of Vocational Behavior 62 (2003) 119-133.

KIDD, J. Emotion: An Absent Presence in Career Theory. Journal of Vocacional Behavior. 52, 275-288 (1998).

FELDMAN, The antecedents and consequences of early career indecision among young adults. Human Resource Management Review 13 (2003) 499-531.

MINOR, M. Coaching para o desenvolvimento. Rio de Janeiro: Qualitymark, 2003.

SALMELA-ARO, K.; TOLVANEN, A.; NURMI, J. Achievement strategies during university studies predict early career burnout and engagement. Journal of Vocational Behavior 75 (2009) 162-172.

PEREIRA, D.F.; TONDO, C. Planejamento de Carreira de herdeiros. In: TONDO, C. Desenvolvendo a empresa familiar e a família empresária. Porto Alegre: Sulina, 2008.

SCHEIN, E. (1996). Identidade profissional: Como ajustar suas inclinações a suas opções de trabalho. São Paulo: Nobel.

SCHERER, K. R.; TRAN, V. Effects of emotion on the process of Organization Learning. In I. Nonaka (Ed.), Handbook of organizational learning and knowledge (pp. 369-392). Oxford, UK: Oxford University Press. 2001.

SPACCAQUERCHE, M. E. Orientação profissional online: uma experiência em processo. Revista Braileira de Orientação Profissional, jun. 2005, vol.6, no.1, p.63-74.

TRAN, V. The influence of emotions on decision-making processes in management teams. L'influence des Emotions sur les Processus de Prise de Décision dans les Equipes de Cadres). Faculte De Psychologie et des Sciences de l'Education. Université de Genève. Thèse No 323. 2004. 